\title{
Diálogos: gênero, política e poder
}

\section{Carla Rodrigues}

\section{Resenha}

OSTERMANN, Ana Cristina; FONTANA, Beatriz.

(Org.). Linguagem, gênero, sexualidade. São Paulo: Parábola, 2010.

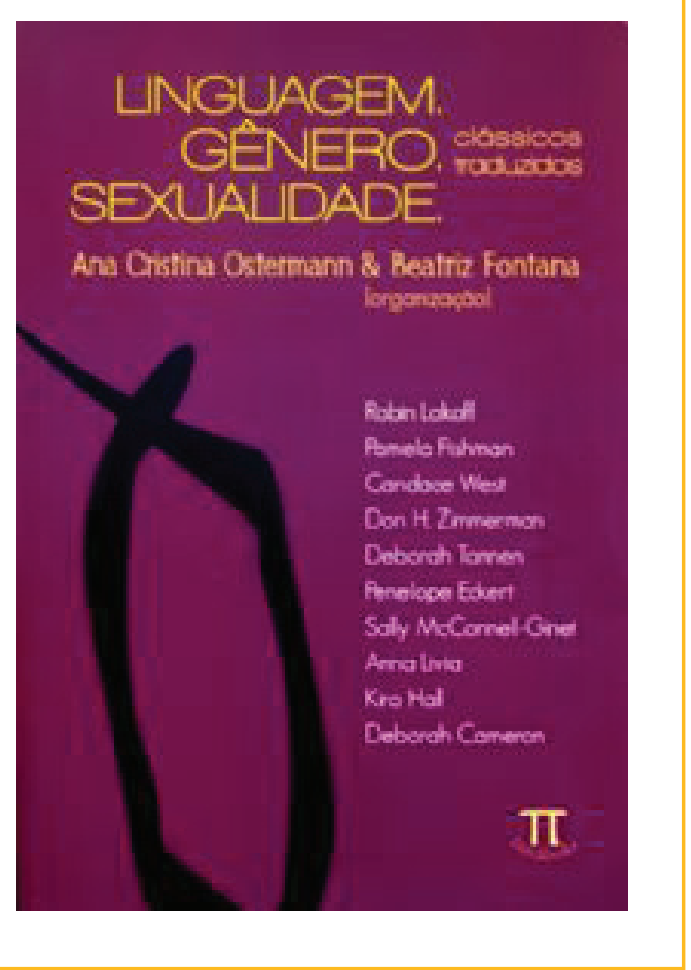

Carla Rodrigues I carla@puc-rio.br

Doutora em Filosofia pela Pontifícia Universidade Católica do Rio de Janeiro (PUC-Rio). Professora do Departamento de ComunicaçãoSocial da PUC-Rio.
Linguagem, gênero e sexualidade, coletânea organizada por Ana Cristina Ostermann e Beatriz Fontana, é uma bem-vinda contribuição ao debate sobre gênero, linguagem e comunicação. Interações comunicacionais, análise de discurso e outras pesquisas da área de Comunicação que contemplem aspectos do uso da linguagem passam a ter uma bibliografia de referência que aborda questões de gênero. Do exemplo mais simples - o uso do termo "homem" como sinônimo de humanidade, consequência de se tomar o masculino como neutro e universal - aos avanços mais recentes e o reconhecimento da discriminação no discurso, a linguagem passou a ser estudada como mais um elemento de interdição do poder às mulheres. Esse campo de estudos sobre a linguagem tornou-se possível a partir da virada linguística e do reconhecimento da linguagem como convenção. Desde Crátilo $^{1}$, a tradição filosófica discutia a "justeza dos nomes": Hermógenes e Crátilo defendem duas posições antagônicas em relação à linguagem. Para ele, as palavras são adequadas às coisas por "natureza", enquanto Hermógenes vai defender a ideia de 
pacto, convenção e consenso. Sócrates critica a teoria convencionalista e adere ao naturalismo, fazendo Crátilo vencer Hermógenes².

Só no final do século XIX começam a surgir os primeiros estudos que, com a teoria linguística de Ferdinand de Saussure ${ }^{1}$, no século XX, sustentarão a linguagem como convenção. As afirmações de Saussure sobre a arbitrariedade do signo e da ligação arbitrária entre significante e significado abrem muitas questões, entre as quais está a possibilidade de pensar sobre 0 caráter supostamente neutro da linguagem. Articule-se a isso a crise da representação, a afirmação de que tudo é discurso, os questionamentos da teoria feminista sobre a construção das diferenças sexuais, e chega-se aos estudos sobre linguagem e gênero dos quais os textos reunidos no volume organizado por Ana Cristina e Beatriz são representativos.

Editados na coleção Clássicos traduzidos da Editora Parábola, a coletânea apresenta os textos em ordem cronológica, o que permite uma compreensão da evolução desses estudos. Estão reunidos desde o pioneiro trabalho de Robin Lakoff, o já clássico Linguagem e lugar da mulher (tradução de Adriana Braga e Édison Luis Gastaldo), de 1975, até 0 artigo de Deborah
Cameron, Desempenhando identidade de gênero: conversa entre rapazes e construção de masculinidade heterossexual, de 1998 (tradução de Beatriz Fontana), em que estão em debate temas contemporâneos como as contribuições da teoria queer para a questão da linguagem.

A partir da abertura proporcionada pelas teorias feministas que mostraram como o gênero é construído, Lakoff analisa a construção da distinção entre "linguagem masculina" e "linguagem feminina", mostrando como o uso da linguagem dita feminina sempre foi um elemento de interdição ao poder. Toda a discussão se dá a partir da ideia de que essa distinção foi construída a fim de manter as mulheres em papéis secundários na sociedade e garantir aos homens 0 privilégio de falar sobre o que "realmente importa". Ao longo do percurso cronológico que o livro se propõe a cumprir, entram em cena textos como

\section{O trabalho que as mulheres realizam nas} interações, em que Pamela Fishman (tradução de Viviane M. Heberle) analisa 52 horas de conversa gravada em áudio entre parceiros íntimos em suas casas. Seguindo a linha dos estudos iniciados por Lakoff, a autora procura demonstrar como homens e mulheres se utilizam, de maneira distinta, de estratégias discursivas: por exemplo, mulheres

PLATÃo. Crátilo. Lisboa: Piaget, 2001.

"Nesse caso, ó Hermógenes, a atribuição dos nomes arrisca-se a não ser uma coisa desprovida de importância, como tu pensas, nem para homens desprovidos de importância ou para qualquer pessoa. E Crátilo diz a verdade quando diz que os nomes pertencem às coisas por natureza e que nem todas as pessoas são artífices dos nomes, mas só aquela que fixa os olhos no nome que é, por natureza, o nome de cada coisa e é capaz de impor a sua forma às letras e às sílabas" (PLATÃ0, 2001, p. 53, 390e). 
fazem três vezes mais perguntas que os homens, o que já havia sido apontado por Lakoff como um sinal de insegurança feminina.

Já Candace West e Don H. Zimmerman, no texto Pequenos insultos: estudo sobre interrupções em conversas desconhecidas e de diferentes sexos (tradução de Ana Cristina 0stermann e Mariléia Sell), mostram a assimetria na maneira como homens interrompem a fala das mulheres, tentando formular uma espécie de divisão sexual da linguagem na qual a interrupção garante aos homens o poder nas interações tidas como dialógicas.

Ainda no tema da interrupção, Deborah Tannen propõe pensar sobre o estereótipo que pesa sobre as mulheres: nunca seria possível interrompêlas porque falam demais. 0 texto Quem está interrompendo? Questões de dominação e controle (tradução de Débora de Carvalho Figueiredo) segue a mesma linha do artigo anterior, mas acrescentando à análise categorias de fala cooperativa e fala não-cooperativa que permitem à autora identificar interrupções como sinal de competição e diferenciá-las de outros estilos de interrupção que não carregariam conotação de poder.

Poder também é o tema do artigo Comunidades de práticas: lugar onde co-habitam linguagem, gênero e poder, de Penélope Eckert e Sally McConnell-Ginet (tradução de Branca Falabella Fabrício). Publicado originalmente em 1992, 0 estudo já está imerso no contexto de discussão sobre a categoria "mulheres" como uma identidade que precisaria ser relacionada a outras características, como posição social, cultura, economia etc. Ao apontar para as mudanças constantes na maneira como homens e mulheres falam, as autoras estavam abrindo um debate sobre os conceitos em que a sociolinguista se apoiava. Era o início dos anos 1990 e tudo que havia sido pensado e discutido desde a chamada virada linguística estava entrando em um longo (e ainda não concluído) processo de questionamento. Nesse percurso, o texto 'É uma menina!': a volta da performatividade à linguística, de Anna Lívia e Kira Hall (tradução de Rodrigo Borba e Cristiane Maria Schnack), marca a entrada na cena teórica dos estudos sobre orientação sexual que floresceram a partir das interrogações abertas pela teoria feminista, e não sem alguma tensão entre as duas.

No percurso cronológico escolhido pelas organizadoras, se chega ao artigo de encerramento do livro, no qual Deborah Cameron vai dialogar com o pensamento de Judith Butler para discutir os estilos de fala tidos como "masculinos" e "femininos", tomados como repetições realizados por "atores sociais que estão esforçando-se para constituírem-se como homens e mulheres 'adequados'”. Tem-se, aí, um importante deslocamento no debate iniciado em Lakoff: a sociolinguística defendia que a linguagem seria resultado de uma construção que se dá a partir de diversos fatores, inclusive 0 gênero. $\mathrm{Na}$ abordagem contemporânea - que Deborah chama de pós-moderna, denominação cada vez mais imprecisa que pretende reunir sob um mesmo 
arcabouço diferentes correntes de pensamento -, a linguagem seria usada para produzir as diferenças de gênero.

Ela está se valendo das afirmações de Butler, para quem não existe uma identidade de gênero "por trás" das expressões de gênero. A filósofa norte-americana defende que a identidade é "performativamente constituída", resultado da leitura das proposições do linguista John Austin a partir do diálogo que ela estabelece com Jacques Derrida.

Será apoiada no pensamento de Derrida que Butler vai reler Simone de Beauvoir e propor uma revisão na premissa que serviu de base para 0 desenvolvimento dos estudos de gêneros. Nos estudos de gênero iniciados a partir de Beauvoir, a hierarquia da oposição binária masculino/ feminino estava dada pela mesma oposição cultura/natureza, estando o masculino e a cultura na parte privilegiada dessa hierarquia e 0 feminino e a natureza na parte inferior. É essa distinção sexo/gênero que Butler vai ao mesmo tempo questionar e amplificar. Questionar por enxergar no par sexo/gênero uma oposição metafísica e por identificar o conceito de gênero ainda funcionando como o sentido, a essência, a substância, categorias ainda dentro da metafísica.
Ampliar por um longo caminho teórico que não se justifica reproduzir aqui, ao propor o gênero como performance, não mais como uma consequência (natural) do sexo.

Entre 1975, quando Lakoff publicou Linguagem e lugar da mulher, e 1998, quando entram em cena os deslocamentos propostos por Butler, há muito a pensar sobre as relações de poder que ainda hoje são intrínsecas a experiência de linguagem, sobre as quais recupero as afirmações de Butler: "A própria noção de diálogo é culturalmente específica e historicamente delimitada"4. Nesse sentido, aprofundar o debate sobre linguagem, gênero e sexualidade e reconhecer que a hierarquia de gênero aparece naquilo que se pretende um diálogo entre iguais é mais do que a edição de um conjunto importante de textos clássicos - é em si um ato político. 


\section{Expediente}

A revista E-Compós é a publicação científica em formato eletrônico da Associação Nacional dos Programas de Pós-Graduação em Comunicação (Compós). Lançada em 2004, tem como principal finalidade difundir a produção acadêmica de pesquisadores da área de Comunicação, inseridos em instituições do Brasil e do exterior.

\section{E-COMPÓS I www.e-compos.org.br I E-ISSN 1808-2599}

Revista da Associação Nacional dos Programas de Pós-Graduação em Comunicação.

Brasília, v.14, n.1, jan/abr. 2011

A identificação das edições, a partir de 2008

passa a ser volume anual com três números.

\section{CONSELHO EDITORIAL}

Afonso Albuquerque, Universidade Federal Fluminense, Brasil Alberto Carlos Augusto Klein, Universidade Estadual de Londrina, Brasil Alex Fernando Teixeira Primo, Universidade Federal do Rio Grande do Sul, Brasil Ana Carolina Damboriarena Escosteguy, Pontifícia Universidade Católica do Rio Grande do Sul, Brasil

Ana Gruszynski, Universidade Federal do Rio Grande do Sul, Brasil Ana Silvia Lopes Davi Médola, Universidade Estadual Paulista, Brasil André Luiz Martins Lemos, Universidade Federal da Bahia, Brasil Ângela Freire Prysthon, Universidade Federal de Pernambuco, Brasil Angela Cristina Salgueiro Marques, Faculdade Cásper Líbero (São Paulo), Brasil Antônio Fausto Neto, Universidade do Vale do Rio dos Sinos, Brasil Antonio Carlos Hohlfeldt, Pontifícia Universidade Católica do Rio Grande do Sul, Brasil Antonio Roberto Chiachiri Filho, Faculdade Cásper Líbero, Brasil Arlindo Ribeiro Machado, Universidade de São Paulo, Brasil Arthur Autran Franco de Sá Neto, Universidade Federal de São Carlos, Brasil Benjamim Picado, Universidade Federal Fluminense, Brasil César Geraldo Guimarães, Universidade Federal de Minas Gerais, Brasil Cristiane Freitas Gutfreind, Pontifícia Universidade Católica do Rio Grande do Sul, Brasil Denilson Lopes, Universidade Federal do Rio de Janeiro, Brasil Denize Correa Araujo, Universidade Tuiuti do Paraná, Brasil Edilson Cazeloto, Universidade Paulista, Brasil Eduardo Peñuela Cañizal, Universidade Paulista, Brasil Eduardo Vicente, Universidade de São Paulo, Brasi Eneus Trindade, Universidade de São Paulo, Brasil Erick Felinto de Oliveira, Universidade do Estado do Rio de Janeiro, Brasil Florence Dravet, Universidade Católica de Brasília, Brasil Francisco Eduardo Menezes Martins, Universidade Tuiuti do Paraná, Brasil Gelson Santana, Universidade Anhembi/Morumbi, Brasil Gilson Vieira Monteiro, Universidade Federal do Amazonas, Brasil Gislene da Silva, Universidade Federal de Santa Catarina, Brasi Guillermo Orozco Gómez, Universidad de Guadalajara Gustavo Daudt Fischer, Universidade do Vale do Rio dos Sinos, Brasil Hector Ospina, Universidad de Manizales, Colômbia Herom Vargas, Universidade Municipal de São Caetano do Sul, Brasil leda Tucherman, Universidade Federal do Rio de Janeiro, Brasil Inês Vitorino, Universidade Federal do Ceará, Brasil Janice Caiafa, Universidade Federal do Rio de Janeiro, Brasil Jay David Bolter, Georgia Institute of Technology Jeder Silveira Janotti Junior, Universidade Federal de Pernambuco, Brasil João Freire Filho, Universidade Federal do Rio de Janeiro, Brasil
John DH Downing, University of Texas at Austin, Estados Unidos José Afonso da Silva Junior, Universidade Federal de Pernambuco, Brasil José Carlos Rodrigues, Pontifícia Universidade Católica do Rio de Janeiro, Brasil José Luiz Aidar Prado, Pontifícia Universidade Católica de São Paulo, Brasil José Luiz Warren Jardim Gomes Braga, Universidade do Vale do Rio dos Sinos, Brasil Juremir Machado da Silva, Pontifícia Universidade Católica do Rio Grande do Sul, Brasil Laan Mendes Barros, Universidade Metodista de São Paulo, Brasil Lance Strate, Fordham University, USA, Estados Unidos Lorraine Leu, University of Bristol, Grã-Bretanha Lucia Leão, Pontifícia Universidade Católica de São Paulo, Brasil Luciana Panke, Universidade Federal do Paraná, Brasil Luiz Claudio Martino, Universidade de Brasília, Brasil Malena Segura Contrera, Universidade Paulista, Brasil Márcio de Vasconcellos Serelle, Pontifícia Universidade Católica de Minas Gerais, Brasi Maria Aparecida Baccega, Universidade de São Paulo e Escola Superior de Propaganda e Marketing, Brasil

Maria das Graças Pinto Coelho, Universidade Federal do Rio Grande do Norte, Brasil Maria Immacolata Vassallo de Lopes, Universidade de São Paulo, Brasil Maria Luiza Martins de Mendonça, Universidade Federal de Goiás, Brasil Mauro de Souza Ventura, Universidade Estadual Paulista, Brasil Mauro Pereira Porto, Tulane University, Estados Unidos Nilda Aparecida Jacks, Universidade Federal do Rio Grande do Sul, Brasil Paulo Roberto Gibaldi Vaz, Universidade Federal do Rio de Janeiro, Brasil Potiguara Mendes Silveira Jr, Universidade Federal de Juiz de Fora, Brasil Renato Cordeiro Gomes, Pontifícia Universidade Católica do Rio de Janeiro, Brasi Robert K Logan, University of Toronto, Canadá

Ronaldo George Helal, Universidade do Estado do Rio de Janeiro, Brasil Rosana de Lima Soares, Universidade de São Paulo, Brasil Rose Melo Rocha, Escola Superior de Propaganda e Marketing, Brasil Rossana Reguillo, Instituto de Estudos Superiores do Ocidente, Mexico Rousiley Celi Moreira Maia, Universidade Federal de Minas Gerais, Brasil Sebastião Carlos de Morais Squirra, Universidade Metodista de São Paulo, Brasil Sebastião Guilherme Albano da Costa, Universidade Federal do Rio Grande do Norte, Brasil

Simone Maria Andrade Pereira de Sá, Universidade Federal Fluminense, Brasil Tiago Quiroga Fausto Neto, Universidade de Brasília, Brasil Suzete Venturelli, Universidade de Brasilia, Brasil

Valério Cruz Brittos, Universidade do Vale do Rio dos Sinos, Brasil Valerio Fuenzalida Fernández, Puc-Chile, Chile Veneza Mayora Ronsini, Universidade Federal de Santa Maria, Brasil Vera Regina Veiga França, Universidade Federal de Minas Gerais, Brasil

\section{COMISSÃO EDITORIAL}

Adriana Braga I Pontifícia Universidade Católica do Rio de Janeiro, Brasil Felipe Costa Trotta I Universidade Federal de Pernambuco, Brasil CONSULTORES AD HOC

Édison Gastaldo I Universidade Federal Rural do Rio de Janeiro, Brasil Gisela Grangeiro da Silva Castro, Escola Superior de Propaganda e Marketing, Brasil Helio Kuramoto, Instituto Brasileiro de Informação em Ciência e Tecnologia, Brasil Juliano Maurício de Carvalho, Universidade Estadual Paulista, Brasil Maria Helena Weber, Universidade Federal do Rio Grande do Sul, Brasi Paulo Carneiro da Cunha Filho, Universidade Federal de Pernambuco, Brasil Vera Regina Veiga França, Universidade Federal de Minas Gerais, Brasil EDIÇÃO DE TEXTO E RESUMOS I Susane Barros SECRETÁRIA EXECUTIVA I Juliana Depiné EDITORAÇ̃̃o ELETRÔNICA I Roka Estúdio
COMPóS I www.compos.org.br

Associação Nacional dos Programas de Pós-Graduação em Comunicação

Presidente

Itania Maria Mota Gomes

Universidade Federal da Bahia, Brasil

itania@ufba.br

Vice-presidente

Julio Pinto

Pontifícia Universidade Católica de Minas Gerais, Brasil juliopinto@pucminas.br

Secretária-Geral

Ana Carolina Escosteguy

Pontifícia Universidade Católica do Rio Grande do Sul, Brasil carolad@pucrs.br 